\title{
TRADITIONAL TRADE VS. E-COMMERCE: DOES PRODUCT QUALITY HAVE THE SAME VALUE? A CASE STUDY OF THE CITY OF ANTANANARIVO, MADAGASCAR
}

\author{
Tsirinirina Solofomiarana Rapanoel ${ }^{1}$, Pierre Benjamin Rakotomahenina ${ }^{*}{ }^{\mathbb{W}}, \mathrm{T}$. \\ Ramanankonenana ${ }^{3}$ \\ ${ }^{1}$ Senior Lecturer, Qualification in Management Sciences, Faculty of Economics, Management and \\ Sociology (EGS), University of Antananarivo, Madagascar \\ *2 Senior Lecturer, Management Department, Faculty of Economics, Management and Sociology- \\ University of Antananarivo, Madagascar \\ ${ }^{3}$ Doctor in Agronomic Sciences, Qualification in Agro-Management, Higher School of Agronomic \\ Sciences (ESSA), University of Antananarivo, (Consultant in Organization and Economic Studies), \\ Madagascar
}

DOI: https://doi.org/10.29121/ijetmr.v7.i12.2020.829

Article Citation: Tsirinirina Solofomiarana Rapanoel, Pierre Benjamin Rakotomahenina, and T. Ramanankonenana. (2020). TRADITIONAL TRADE VS. ECOMMERCE: DOES PRODUCT QUALITY HAVE THE SAME VALUE? A CASE STUDY OF THE CITY OF ANTANANARIVO, MADAGASCAR. International Journal of Engineering Technologies and Management Research, 7(12), 33-44. https://doi.org/10.29121/ijetmr.v7 .i12.2020.829

Published Date: 21 December 2020

Keywords:

Satisfaction

Marketing

E-Commerce

Customer

Needs

\section{ABSTRACT}

Globalization has caused a rapid evolution of commerce in all countries, including developing countries like Madagascar. This is reflected in the emergence of new, more accessible and faster distribution channels with the development of the Internet. Today, customers have a wider choice of products to satisfy their needs and personal convenience. To get closer to customers, traders resort to a range of sales channels. Online and traditional commercial transactions have distinct features which may not match up with customers' real expectations. Indeed, social networks have grown rapidly in Madagascar since 2010 and have brought about a change that could disrupt customers' habits. Moreover, the perception of quality might not be the same in each case. This study is intended to compare the perception of product quality from these two channels in order to assess customer satisfaction. The survey was conducted among a sample of 85 people from different socio-professional categories (SPCs), including students, employees, functionaries, unemployed, liberal professionals and stay-at-home persons. Multivariate analyses show the relationships between the expectations of each SPC and the channels used. The results highlight the mismatch between the needs and expectations of each category of customers according to the mode of business operation.

\section{INTRODUCTION}

New Information and Communication Technologies (NICTs) are increasingly affecting business operations, as with the emergence of e-commerce. In Madagascar, online commerce still has a long way to go if we refer to dedicated websites. Rather than rushing Malagasy costumers, these sites have opted for a halfway solution between ecommerce and direct trade. According to UNCTAD's 2017 Information Economy Report, most African countries

(C) 2020 The Author(s). This is an open access article distributed under the terms of the Creative Commons Attribution License, which permits unrestricted use, distribution, and reproduction in any medium, provided the original author and source are credited. 
Traditional Trade Vs. E-Commerce: Does Product Quality Have the Same Value? A Case Study of The City of Antananarivo, Madagascar

including Madagascar are not ready for e-commerce yet. UNCTAD's index helps countries understand their strengths and weaknesses. African countries still suffer from low Internet penetration rate, however profit margins are huge and Africa can take advantage of the opportunities offered by e-commerce. UNCTAD Secretary-General Mukhista Kituya stated: "As the digital economy expands and more business activities are affected, it becomes more important for governments to consider policies that can help to harness e-commerce for sustainable development."

The Internet has revolutionized the world of commerce through the creation of e-commerce or electronic commerce. In the 1970's, e-commerce consisted only of electronic transactions and computerized data exchanges between companies. It was only in the 1980's, with the proliferation of credit cards and automated teller machines (ATMs), that the electronic payment system gradually appeared on websites.

In Antananarivo, the capital of Madagascar, social networks are widely used by various trader categories, and the city has become embroiled in a battle between different methods of purchasing and distribution. While one in ten persons declared to have made at least one online purchase in 2017, the number grew to one in three persons in 2018 (35 percent increase). Nevertheless, despite the benefits of online commercial transactions, many people prefer to adopt the traditional direct purchase method. One question stimulates a debate: are quality expectations the same for online and traditional commerce? This question led us to set the objective of identifying the levels of perception of the products offered by these two distribution channels.

The following assumption was put forward: direct commerce is valued more highly than online commerce because of the quality of the product offered. On one hand, in direct trade, the product quality is perceived physically through direct observation by the customer. On the other hand, online trade involves the risk of non-matching between the product displayed on the website and the product actually delivered.

\section{THEORICAL AND CONCEPTUAL FRAMEWORK}

\subsection{QUALITY OF A PRODUCT OR A SERVICE}

Various organizations and experts have attempted to define "quality". The concept of quality is difficult to define and can be very subjective. According to ISO 9000, quality is the ability of a product or service to satisfy stated needs. As such, one can say that a good or a service has good quality only when it satisfies the requirements specified by the client. Moreover, the satisfaction of such requirements involves precision, leaving no room for approximation. Expectations about a product or service are based on reliability, durability, compliance with standards and performance.

According to AFNOR, a quality product or service is a product whose characteristics allow it to satisfy the stated or implicit needs of customers. Quality is therefore a relative concept based on needs. Quality is a basic concept that the public perceives more and more in a sensory and affective relation to the object, but which also relates to rational judgment; the notion of quality is inseparable from the qualities of the product (Giordano, 2006)

Today's traditional trade uses business practices that involves critical contact between the customer and the seller. In addition to the use of tools (computer, management software...), jobs related to this method of trade first and foremost require relational skills and a good knowledge of the products. Customers have become increasingly demanding in terms of service quality, sedentary salesman's advice (in store) and product quality.

E-commerce does not involve direct contact with the customer. Despite transaction speed and accessibility, the success of online transactions is based more on trust, given the risks that could occur. Trust building is based on three criteria: integrity, capacity and goodwill (Lee and Turban, 2001). Building trust provides customers with a sense of assurance that reduces risks and vulnerabilities including their own security and an invasion to their privacy during transactions (Beldad et al., 2010).

\subsection{MULTICHANNEL MARKETING AND CUSTOMER RETENTION}

The multi-channel marketing environment has become more widespread in recent years. A marketing strategy that uses multiple channels has become an important tool to motivate customers to shop more frequently while improving the interaction between sellers and buyers towards a sustainable relationship (Hansotia and Rukstales, 2002; Rangaswamy and Van Bruggen, 2005). 
Tsirinirina Solofomiarana Rapanoel, Pierre Benjamin Rakotomahenina, and T. Ramanankonenana

In addition, firms are trying to implement strategies to increase customer retetion and avoid customer churn, as the costs of customer acquisition are much higher than that of retention. An additional effort in terms of customer retention is thus more profitable for firms (Pfeifer and Farris, 2004; Reichheld and Sasser, 1990; Gupta and Lehmann, 2003).

\subsection{SOCIAL NETWORKING AND CUSTOMER RELATIONSHIP MANAGEMENT (CRM)}

Social media networking has emerged as a revolution in the digital age in recent decades, with major mpacts on the business world. Researchers have identified several benefits from social media, including facilitating the emergence of creative online users for content creation, interaction, and interoperability (Berthon et al., 2012). The fundamental nature of social media as a platform for customers to interact with and influence one another has a more direct impact on brand communities, and it produces higher response rates and greater customer engagement than traditional marketing methodologies that focus only on firm-consumer relationship (Trusov et al., 2009).

Social media applications are also transforming the role of online users from passive consumers of information to active participants in creating and sharing information with one another: videos, stories, photos (Lenhart et al., 2010). In addition to facilitating interpersonal communications, social media have enabled customers to interact with business organizations and have empowered them to take an active role in the search for creativity (Prahalad and Ramaswamy 2004). Currently, managers are integrating social media applications into customer relationship management (CRM) systems to develop new capabilities that improve customer experience and satisfaction (Trainor et al., 2014). This merger of existing CRM systems with social media has extended the concept of CRM to incorporate a more collaborative, interactive, and network-focused approach to managing customer relationships (Trainor et al., 2014). The recently coined term "Social Customer Relationship Management" or Social CRM describes this new CRM system (Greenberg, 2010). Marketing scholars define social CRM as "the integration of customer-focused activities, including processes, systems, and technologies, with emergent social media applications to engage customers in collaborative conversations and enhance customer relationships" (Trainor, 2012). Many organizations and firms have recognized the importance and the potential of social CRM and have made considerable investments in the system. Researchers have shown that CRM technologies alone rarely add value and are most effective when combined with other firm resources (Chang et al., 2010; Jayachandran et al., 2005; Srinivasan et al., 2005; Trainor et al., 2014).

\section{METHODOLOGY}

\subsection{STRUCTURED INTERVIEW}

Exploratory interviews have been carried out at the beginning of the survey to determine the study population. Semi-directive interviews were conducted with vendors, customers, consultants and other NTICs experts. Discussions with these people and observations have guided the selection of population categories to be surveyed.

Subsequently, structured interviews were conducted in a few locations within the city of Antananarivo in accordance with the guidelines for exploratory interviews. During these interviews, the interviewer asked questions according to a strict predefined protocol (the objective was to avoid that the interviewee goes beyond the questions asked and the scope defined). Interviews were conducted in several highly populated locations in the city of Antananarivo, including Antanimena, Ampefiloha, 67ha, Alarobia, Ankazomanga, and Ankatso, to achieve significant diversification of the responses. Structured interviews present the advantage of minimizing misunderstanding by the interviewee and focusing the survey.

\subsection{SAMPLING AND DATA COLLECTION}

Once the characteristics of individuals have been determined based on the interviews, the next step is to calculate the sample study. The basic sample size calculated using sampling formula $\left(n=\left[z^{2} p(1-p)\right] /\left[e^{2}\right]\right)$ is 385 people. However, given the homogeneity of some groups according to the experts interviewed earlier, the number was adjusted downwards. The purposive sampling method was used to select the respondents. Consequently, the number of respondents, taking into account the interviews carried out, was 85 people.

International Journal of Engineering Technologies and Management Research 
Traditional Trade Vs. E-Commerce: Does Product Quality Have the Same Value? A Case Study of The City of Antananarivo, Madagascar

\subsection{DATA PROCESSING}

The first step in testing the hypothesis is to identify SPCs in order to determine their proportions. The next step is to determine the characteristics of each SPC according to a number of criteria.

\subsection{MOTIVES ASSOCIATED WITH EACH PURCHASING METHOD}

Through the surveys we have conducted, the research is based on determining the proportions of each of the motives behind customers' choice. The most likely motives for choosing a purchasing method identified through observation are presented in the form of a predefined list to customers. First, in the case of direct purchasing, the list of motives includes the following: transparency of the offer, product quality, and price, interaction between the customer and the seller, and the lack of access to the Internet. Second, in the case of online purchase, the list includes originality, lack of time, product quality, price and accessibility.

\subsection{DETERMINATION OF PREFERENCES ACCORDING TO THE SPC FOR EACH PURCHASING METHOD}

Each SPC has a different lifestyle. Therefore, the motives of these groups of people could vary according to the purchasing method. This information will help situate each purchasing method and identify the reasons that foster its adoption.

The variables to be manipulated in this analysis include SPCs and the motives for selecting a purchasing method. The purpose of the study to establish the relationship between satisfaction levels, the product purchasing method and their respective SPCs, which are all qualitative variables. The appropriate statistical analysis tool is a multivariate analysis, considering these types of variables. The Multiple Correspondence Factor Analysis (MCA) was therefore applied. The results presented are in the form of a two-dimensional symmetrical graph presenting the two factoral axis that contain the most relevant information on the studied phenomenon.

\subsection{IDENTIFICATION OF CHARACTERISTIC TYPES OF GOODS}

Beyond preferences, it is important to identify the types of goods that are most characteristic of each SPC and for each purchasing method. This approach presents the advantage of determining the most popular items for each SPC as well as their purchasing habits.

The variables to be manipulated in this step are: SPC, type, frequency of purchase, and types of goods purchased. Since these variables are qualitative in nature and the relationship between them need to be established, the most appropriate analysis tool is the Multiple Correspondence Factor Analysis (MCA). The results are presented as a twodimensional representation of the two factoral axes.

\section{RESULTS AND DISCUSSIONS}

\subsection{DESCRIPTION OF RESPONDENTS BY SPCS}

Figure 1 provides a snapshot of the characteristics of respondents. The percentage is also provided for each SPC. 


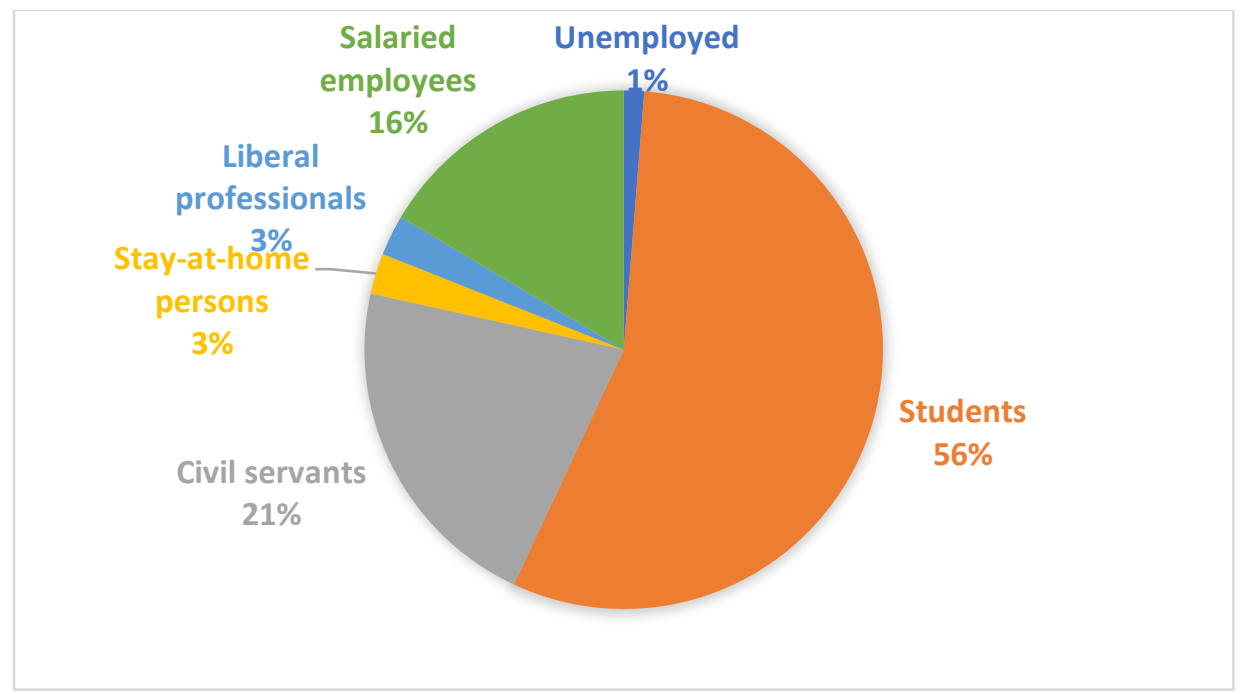

Figure 1: SPCs of respondents

The selection of SPCs is based on a grouping of the population into homogeneous sections for the most frequently observed activities. These activities are part of the customers' daily lives. In other words, customers must belong to one of the SPCs identified. In our study, students account for more than half of respondents (56 percent), followed by employees (37 percent) formed by civil servants (21 percent) and private sector employees (16 percent), in second and third place respectively. Liberal professionals and the unemployed represent only 7 percent of respondents.

\subsection{DIRECT OR TRADITIONAL PURCHASING METHOD}

The evolution of technology continues to have an enormous impact in the world of commerce, including on customers' purchasing behavior. Given the plurality of needs to be satisfied, it is appropriate to focus only on the criteria for selecting this purchasing method and on identifying the categories of goods that promote such practice.

\subsection{REASONS FOR TRADITIONAL PURCHASING METHOD}

There are several reasons why customers continue to practice the traditional purchasing method even though technology offers multiple options for acquiring a good. The figure below shows the main reasons that justify customers' choices.

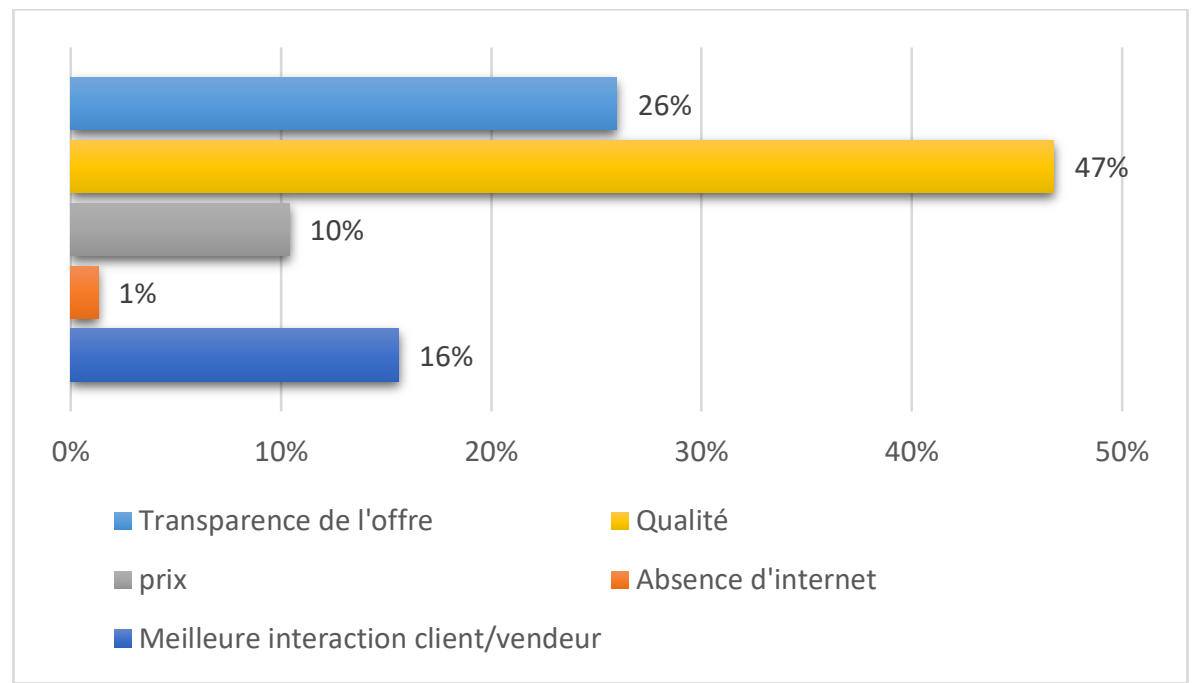

Figure 2: Primary reasons for traditional purchasing method 
Being able to directly observe the quality of the product and/or service is the main reason for almost half of the respondents (47 percent). The second most important reason is product assurance through the transparency of the offer (26 percent). A good client/seller interaction, price and the lack of access to the Internet account for 10 percent, 16 percent and 1 percent respectively, i.e. almost a quarter of respondents.

\subsection{PREFERENCES FOR TRADITIONAL PURCHASING METHOD BY SPC}

Each SPC has its preferences about the choice of the purchasing method. These preferences may include product quality, offer transparency, negotiable price, buyer/seller interaction, or simply a lack of access to the Internet. Figure 3 shows the primary reasons for such choices.

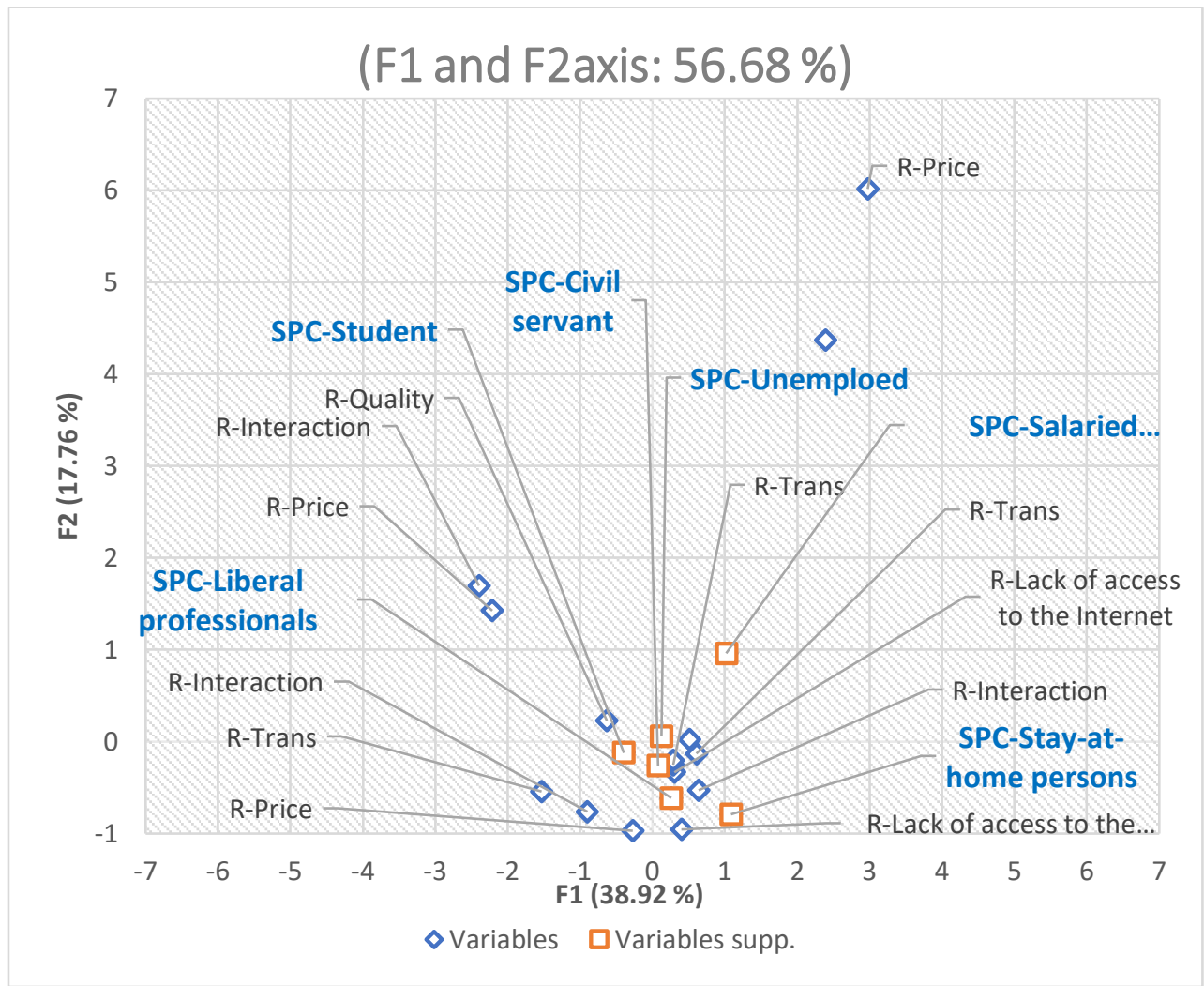

Figure 1: Reasons to opt for direct purchasing, by SCP

\section{Caption}

\section{R-Trans: Offer transparency}

This graphical representation shows only 56.68 percent of the information on the studied phenomenon, and focuses mainly on the factoral axis F1 with 38.92 percent. This figure shows that the behavior of the different SPCs is homogeneous since they are in the same position. In other words, each SPC has no specific reason of its own to adopt the traditional purchasing methods. However, it should be pointed out that the SPC-Salaried employees, i.e. private sector employees, behave differently from the other SPCs.

\subsection{TYPE OF GOODS FOR DIRECT PURCHASING}

Through a direct contact with the seller and the product, a wide range of choices is available to the customer. At this stage, SPCs most typical to the study for which complete data are available include students, salaried employees, and civil servants. The main categories of goods purchased include clothing or footwear, Hi-Tech products (telephone, computer), cosmetics, and furniture. In addition, the frequency of purchase of such goods can be either 
spontaneous, need-based, rarely or several times a month. To illustrate the patterns of direct purchasing, Figure 4 presents the main product categories most often purchased by customers based on their purchasing habits and according to their SPCs.

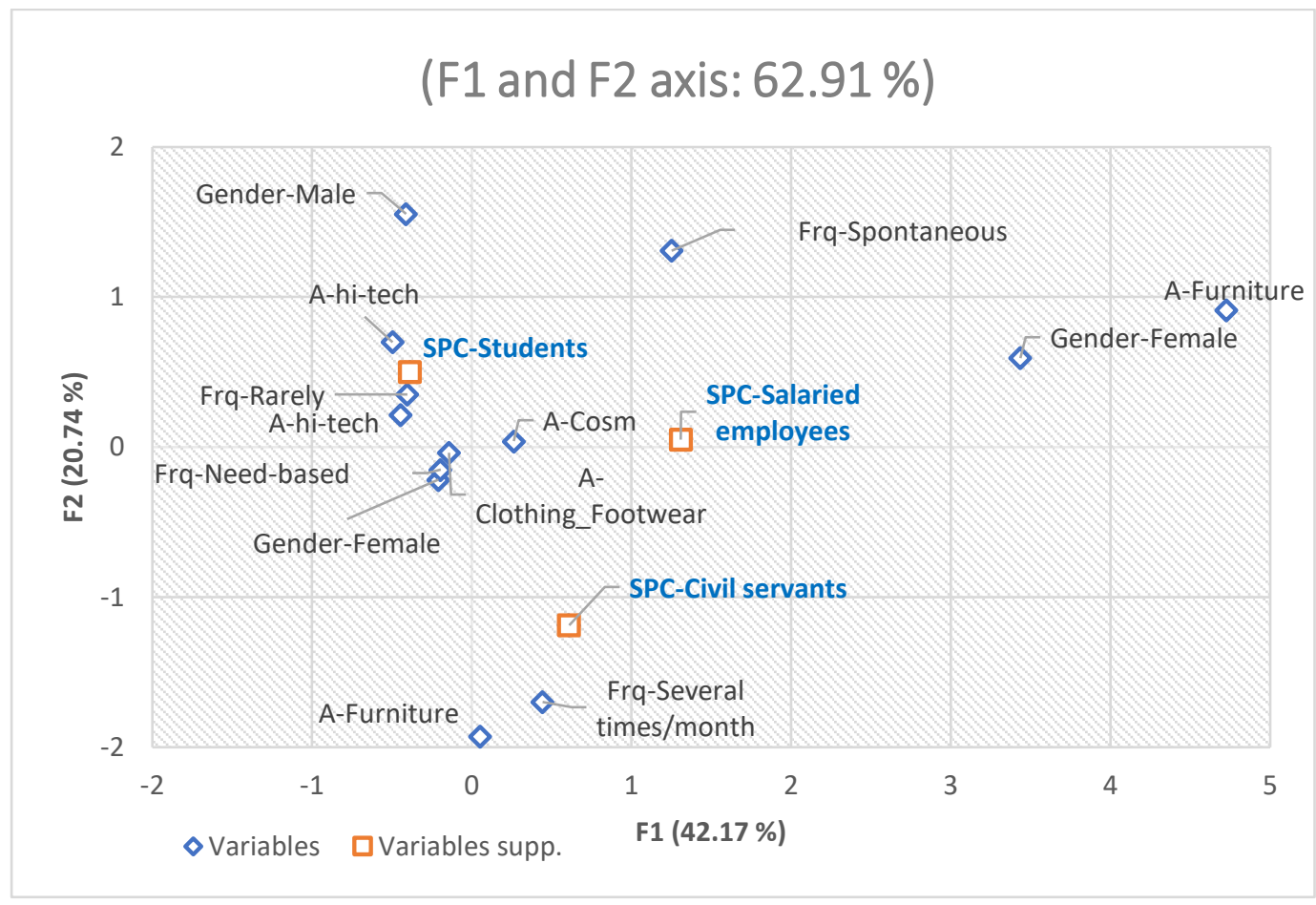

Figure 2: Categories of goods for direct purchasing by SPCs

\section{Caption}

A-Cosm: Cosmetic products

Cloth_Footwear: Clothing and Footwear

The two-dimensional Figure 4 shows 63 percent of the studied phenomenon with respectively 42.17 percent and 20.74 percent for F1 and F2 axis. This figure should be read as a function of the distance between the points. The smaller the distance, the more typical the variables are for the studied SPC. In our case, civil servants are characterized by high purchase frequency "Frq-Several times/month" and are much more interested in furniture rather than "Hi-Tech" products. As far as students are concerned, their purchasing frequency is rare and is characterized by an increased interest in Hi-Tech products, especially for the male gender. The female gender is more interested in clothing and footwear, and cosmetics. It is important to note that students, who purchase on a need basis, are less interested in furniture than civil servants and salaried employees.

\subsection{ONLINE PURCHASING}

The evolution of technology continues to have an enormous impact in the world of commerce. Customers now have the ability to shop online. It is therefore important for us to clarify the motives that drive customers to opt for this purchasing method. Online shopping emerged as a result of technological breakthrough. Consumers see in this phenomenon a mean to satisfy their needs. Figure 5 shows the main reasons why consumers opt for online purchasing. 
Traditional Trade Vs. E-Commerce: Does Product Quality Have the Same Value? A Case Study of The City of Antananarivo, Madagascar

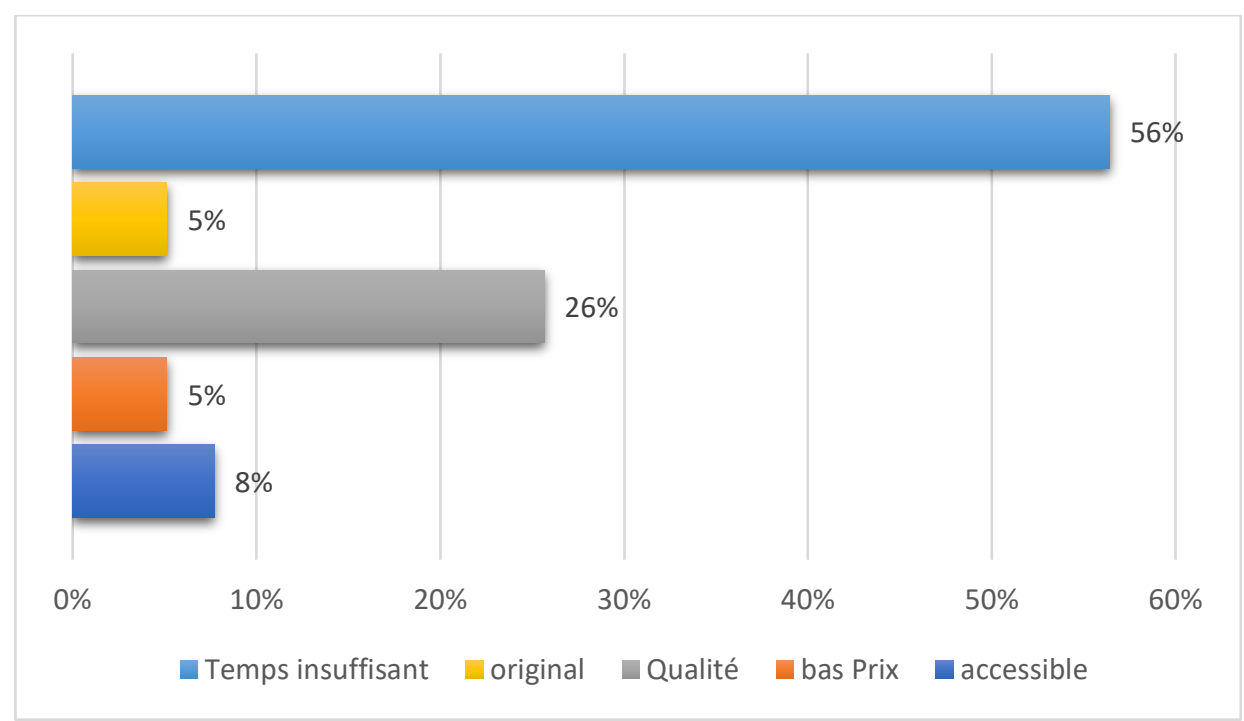

Figure 5: Primary reasons for online purchasing

The above figure shows that more than half of people who buy online ( 56 percent) indicated lack of time as the main reason to opt for this purchasing method. Product quality is in second place (26 percent). Originality, accessibility and low price matter little in choosing online commerce ( 5 percent, 8 percent and 5 percent, respectively).

\subsection{PREFERENCES FOR ONLINE PURCHASING BY SPC}

Online purchasing is more advantageous in terms of travel and time spent by consumers searching for the items they need. However, it requires the availability of suitable technological means that could make the difference in the preferences of each SPC.

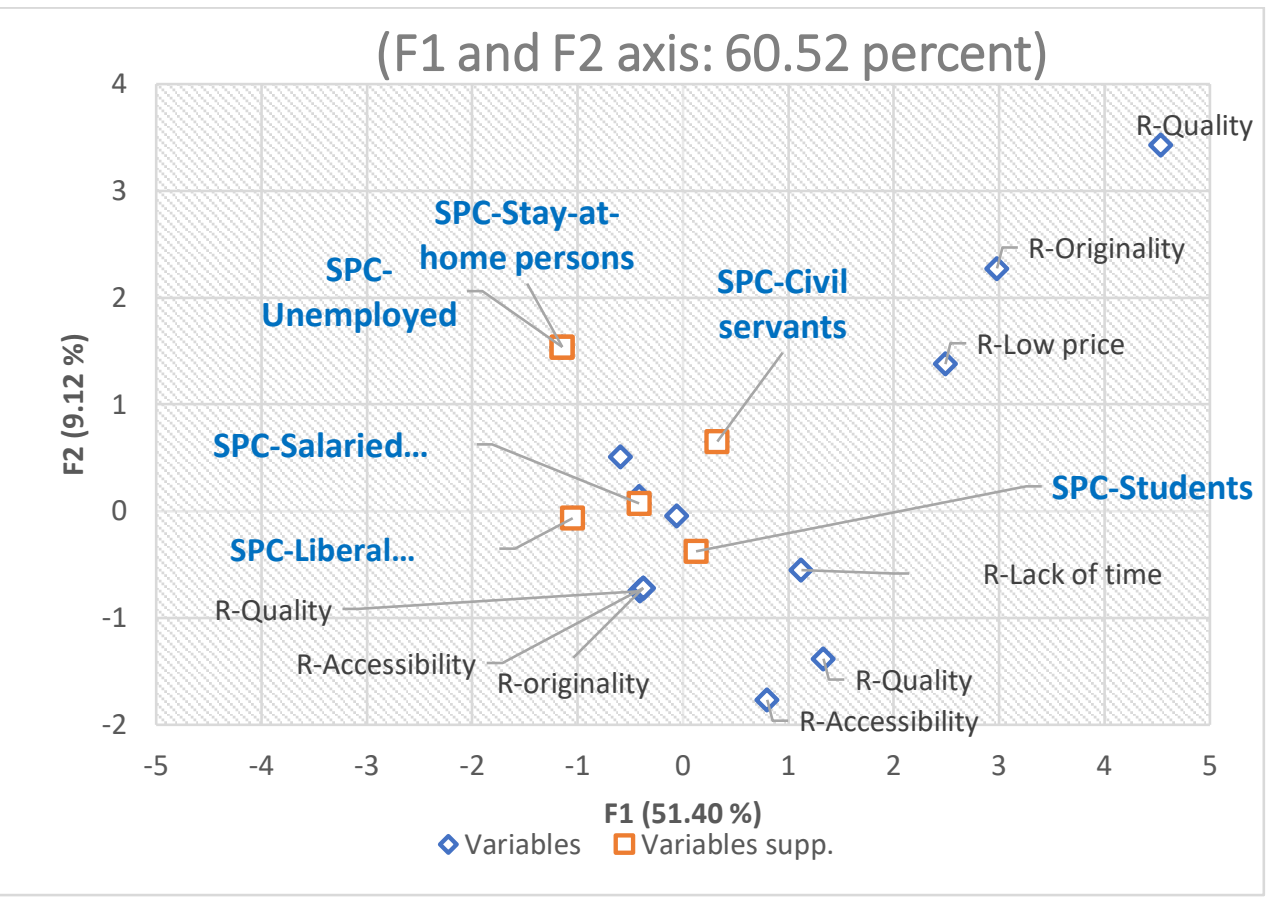

Figure 6: Reasons for choosing online purchasing, by SCP 
The MCA two-dimensional graphic representation shows 60 percent of the studied phenomenon, of which 51 percent are found on F1 factoral axis only. Figure 6 shows similarities in the purchasing behaviors of students, salaried employees, civil servants and liberal professionals SPCs.

\subsection{TYPE OF GOODS FOR ONLINE PURCHASING}

The specificity of online purchasing emphasizes that appropriation of new technologies is essential. Clothing/footwear, furniture, cosmetics and Hi-Tech products are the categories of goods frequently purchased online. Like direct purchasing, online purchasing can be made on a need basis, but rarely spontaneously. It can take place several times a month. Only data for students and civil servants SPCs were fully available in the database. As such, Figure 6 allows to identify of the categories of goods purchased online for these two SPCs only.

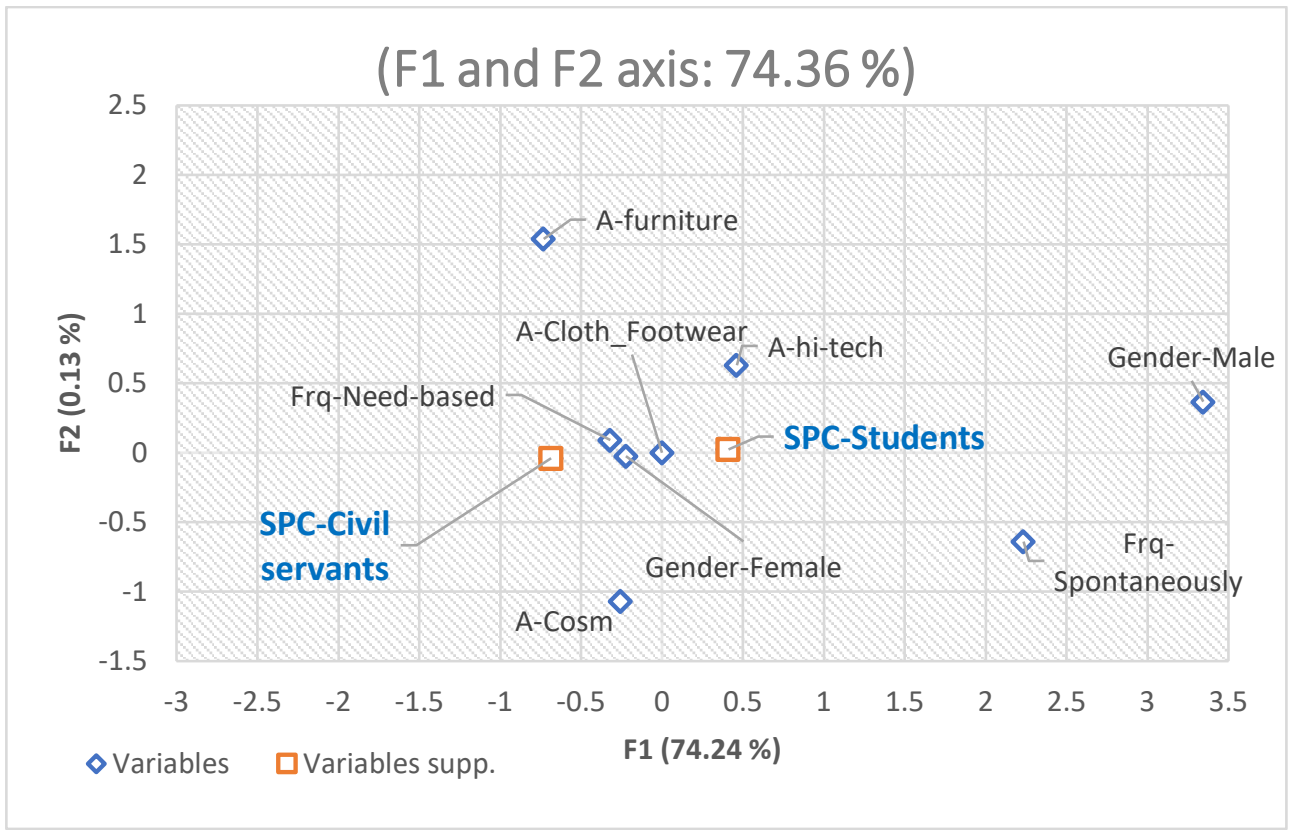

Figure 7: Reasons to opt for online purchasing, by SPC

Figure 7 shows 74 percent of the variability of the studied phenomenon, almost all of it being observed on the F1 factoral axis. This figure can also be read as a function of the distance between the variables. According to the figure above, civil servants opt for online purchasing on a need basis, as do students. Students are much more interested in clothing and footwear as well as Hi-Tech products compared to civil servants. The latter are more interested in cosmetics and furniture.

\subsection{ROLE OF PRODUCT QUALITY IN THE CHOICE OF THE PURCHASING METHOD}

Theoretically, quality is inseparable from needs satisfaction, which can be very different from one consumer to another. In other words, satisfaction cannot be achieved without a quality product and the concept of quality is inseparable from the qualities of the product (Giordano, 2006). This statement is confirmed in Figure 1, which shows that respondents' choice is based on the quality of the product (47 percent of respondents, including students and civil servants). The ability to verify whether the product really meets expectations at the time of purchase is one of the key strengths of traditional commerce, and is reflected in the transparency of the offer, which accounts for 26 percent of respondents.

The main block to online purchasing is trust. Indeed, when purchasing a product and/or a service online, customers face the constraint of the physical absence of a real interlocutor or representative. Moreover, the degree of certainty is limited. Product quality comes second only for 26 percent of respondents. This is in line with the idea that the integrity of the e-seller is decisive in online commerce (Lee and Turban, 2001), much more so than the quality of the product or service itself. Figure 2 shows homogeneous behaviors of the different SPCs, except for SPC- 
Traditional Trade Vs. E-Commerce: Does Product Quality Have the Same Value? A Case Study of The City of Antananarivo, Madagascar

Salaried employees. Actually, physical observation represents the main advantage of direct commerce for all the SPCs. Nevertheless, private sector employees have much less time for online purchasing because of possible overtime work even on weekends, during which all the other SPCs are making direct purchases.

\subsection{RELATIONSHIPS BETWEEN SPCS AND THE TYPES OF GOODS}

This study focuses on consumer goods, and once again, a distinction is made between durable consumer goods such as cars, household equipment, telephones, etc. and non-durable consumer goods such as perfumes, cosmetics, food and fuel. The goods listed in our survey questionnaire are both durable and non-durable goods. These types of goods have been selected to point up the most consumed products for both channels, i.e. clothing and footwear, HiTech products, cosmetics/beauty products, and furniture (Figure 4).

In the case of traditional trade, the crossing of "purchase frequency" and "types of goods" variables with the SPCs reveals, firstly, that students rarely make purchases and when they do, they mostly buy Hi-Tech products. Secondly, salaried employees who make spontaneous purchases most often buy cosmetic products. Finally, civil servants frequently buy furniture and make purchases several times a month (Figure 7). As regards electronic products, purchases are generally made on a need basis by both students and civil servants. The low purchasing frequency of this type of customers explains the high cost of acquiring new customers (Gupta and Lehmann, 2003) for salespeople.

It is noted that the choice of the type of good and the frequency of purchase depend largely on the means of each SPC. The purchase of clothing and footwear is a common act, as they represent basic goods; however, it is characterized by a frequency of purchase that is higher than the other goods. This high purchasing frequency is an opportunity for entrepreneurs as firms will be able to motivate consumers' participation in the creation of new products (Prahalad and Ramaswamy, 2004), which could lead to a better match between supply and demand for a given product.

Goods that are specific for each SPC include furniture and Hi-Tech products: students do not have a preference for this type of goods, unlike civil servants who demonstrate a surplus of confidence in the traditional sale of furniture.

\subsection{COMBINATION OF TRADITIONAL AND E-COMMERCE}

We can identify two advantages of traditional trade: the quality of the product and the quality of human contact. In our study, traditional trade is known for the quality of the products it offers, which remains the primary reason why customers opt for this type of commerce (Figure 2). Other factors to be taken into account include expertise, the embodiment of "values" and customer service. Customers need to become familiar with the product before they buy it. Therefore, they need to see, touch, smell, and even try the product. This ensures a greater transparency of the offer which helps consumer confidence (Beldad et al., 2010).

The aim of a good product is not only to satisfy the customer, but to create a good image for the firm (stores). But direct traders can also use social media by adopting a multi-channel strategy (Hansotia and Rukstales, 2002; Rangaswamy and Van Bruggen, 2005). In this way, product quality will not be the only factor that matters in commercial operations as the trader will also seek to establish a strong and lasting relationship with the buyer.

The proximity between customers and traders is a key factor in traditional trade. Through this channel, customers go to specialized shops to buy products that require expertise, such as pharmaceutical products. Despite running small businesses, these small traders apply basic CRM principles without knowing it. Nevertheless, some traders do not apply the concept of social CRM yet and simply make direct trade, giving rise to opportunity costs. Managerial implications will be addressed to these types of traders, who must be convinced that the use of CRM technologies alone is not enough and that a multi-channel strategy must be adopted to achieve business success (Trainor et al., 2014). 


\subsection{STUDY LIMITATIONS}

Facebook and Messenger are the most widespread social media platforms used in Madagascar. Although other social networks are used, the scope of the study was limited to these two platforms.

To get the opinions of customers, the study attempted to segment customers based on the most representative socio-professional categories (SPCs) among the study population. The determination of SPCs depends to a large extent on the experience of the researcher as well as the expertise of the interviewees during the preparatory phase. Therefore, other categories of customers may not be represented by the selected SPCs.

\section{CONCLUSION}

Customer motivations are different for these two purchasing methods. In the case of traditional trade, they include - by order of preference - product quality, offer transparency and customer/seller interaction. Customers evaluate product quality primarily through the transparency of the offer and the interaction that exists between the seller and the customer, which are the drivers of satisfaction with product quality. These three factors represent the strengths of traditional trade. In the case of online commerce, the study found out that lack of time is the first motivation for online purchases, followed by product quality and accessibility. Customers' lack of time is the primary reason for online purchases, the quality factor comes second and is perceived only upon delivery. It is a delicate and sometimes disappointing moment when the product does not meet the quality expectations. These results confirm our initial hypothesis. However, some other considerations come to mind, including product availability and proximity for online vs. traditional trade.

\section{SOURCES OF FUNDING}

This research received no specific grant from any funding agency in the public, commercial, or not-for-profit sectors.

\section{CONFLICT OF INTEREST}

The author have declared that no competing interests exist.

\section{ACKNOWLEDGMENT}

None.

\section{REFERENCES}

[1] Beldad, Ardion, Memo de Jong, Michael Steehouder. (2010). How Shall I trust the faceless and the intangible? A literature Review on the Antecedents of Online Trust. . Computers in Human Behavior, pp 857 - 69.

[2] Berthon, Pierre R., Leyland F. Pitt, Kirk Plangger, and Daniel Shapiro. (2012). "Marketing Meets Web 2.0, Social Media, and Creative Consumers: Implications for International Marketing Strategy". Business Horizons, 55, 3, 261-71.

[3] Chang, Woojung, Jeong Eun Park, and Seoil Chaiy. (2010). "How Does CRM Technology Transform into Organizational Performance? A Mediating Role of Marketing Capability". Journal of Business Research, 63, 8, 849-55.

[4] Giordano. (2006). L’approche qualité perçue. Ed Eyrolles.

[5] Greenberg, Paul. (2010). "The Impact of CRM 2.0 on Customer Insight". Journal of Business \& Industrial Marketing, 25, 6, 410-9.

[6] Gupta, Sunil and Donald R. Lehmann. (2003). Customers as Assets. Journal of Interactive Marketing, 17, 1, 924. 
Traditional Trade Vs. E-Commerce: Does Product Quality Have the Same Value? A Case Study of The City of Antananarivo, Madagascar

[7] Hansotia, Behram J. and Bradley Rukstales. (2002). Direct Marketing for Multichannel Retailers: Issues, Challenges and Solutions. Journal of Database Marketing, 9, 3, 259-66.

[8] Jayachandran, Satish, Subhash Sharma, Peter Kaufman, and Pushkala Raman. (2005). "The Role of Relational Information Processes and Technology Use in Customer Relationship Management". Journal of Marketing, 69, 4, 177-92.

[9] Lee Matthew K.0 \& Efraim Turban. (2001). A trust model for consumer internet shopping. International journal of electronic commerce, pp75-92.

[10] Lenhart, Amanda, Kristen Purcell, Aaron Smith, and Kathryn Zickuhr. (2010). Social Media and Young Adults. http://www.pewinternet.org/2010/02/03/social-media-and-young-adults/ (Accessed Nov. 8th 2014).

[11] Pfeifer, Phillip E. and Paul W. Farris. (2004). The Elasticity of Customer Value to Retention: The Duration of a Customer Relationship. Journal of Interactive Marketing 18, 2, 20-31.

[12] Prahalad, Coimbatore K. and Venkat Ramaswamy. (2004). "Co-creation Experiences: The Next Practice in Value Creation”. Journal of Interactive Marketing, 18, 3, 5-14.

[13] Rangaswamy, Arvind and Gerrit H. Van Bruggen. (2005). Opportunities and Challenges in Multichannel Marketing: An Introduction to the Special Issue. Journal of Interactive Marketing, 19, 2, 5-11.

[14] Reichheld, Frederick F. and W. Earl Sasser Jr. (1990). Zero Defections Quality Comes to Services. Harvard Business Review, 68, 5, 105-11.

[15] Srinivasan, Raji and Christine Moorman. (2005). "Strategic Firm Commitments and Rewards for Customer Relationship Management in Online Retailing,". Journal of Marketing, 69, 4, 193-200.

[16] Trainor. (2012). "Relating Social Media Technologies to Performance: A Capabilities-based Perspective,". Journal of Personal Selling and Sales Management, 3, 317-31.

[17] Trainor, James Mick Andzulis, Adam Rapp, and Raj Agnihotri. (2014). "Social Media Technology Usage and Customer Relationship Performance: A Capabilities-based Examination of Social CRM,". Journal of Business Research, 67, 6, 1201-8.

[18] Trusov, Michael, Randolph E. Bucklin, and Koen Pauwels. (2009). "Effects of Word-of-Mouth Versus Traditional Marketing: Findings from an Internet Social Networking Site,". Journal of Marketing, 73, 5, 90102.

[19] UNCTAD. (2017). Rapport sur l'économie de l'information. Numérisation, Commerce et développement. 